\title{
O programa brasileiro Bolsa-Atleta: relações entre o investimento e os resultados esportivos entre 2005-2016
}

The Brazilian program Bolsa-Atleta: relationship between investment and sports results from 2005 to 2016

El programa brasileno Bolsa-Atleta: relación entre financiacón y resultados desportivos entre 2005 -

\author{
Isabelle Plociniak Costa \\ ORCID: https://orcid.org/0000-0002-7761-9640 \\ Universidade Federal do Paraná, Brasil \\ E-mail: isabellepcosta@hotmail.com \\ Caroline Costa \\ ORCID: https://orcid.org/0000-0002-2883-298X \\ Universidade Federal do Paraná, Brasil \\ E-mail: tencarolinecosta@gmail.com \\ Mayara Torres Ordonhes \\ ORCID: https://orcid.org/0000-0001-8014-7923 \\ Universidade Federal do Paraná, Brasil \\ E-mail: mayaraordonhes@hotmail.com \\ Kaio Julio Zamboni \\ ORCID: https://orcid.org/0000-0002-0977-2758 \\ Universidade Federal do Paraná, Brasil \\ E-mail: cavicca@hotmail.com \\ Fernando Renato Cavichiolli \\ ORCID: https://orcid.org/0000-0001-8925-2420 \\ Universidade Federal do Paraná, Brasil \\ E-mail: kaiojulio1997@gmail.com
}

\begin{abstract}
Resumo
O presente estudo teve como objetivo verificar se os investimentos financeiros realizados de forma direcionada à determinadas modalidades esportivas proporciona ao país maiores chances de conquistar medalhas, diplomas ou participações olímpicas. Utilizou-se como amostra as modalidades olímpicas que possuíram atletas contempladas pelo programa brasileiro Bolsa-Atleta entre 2005 e 2016. Inicialmente, realizou-se o levantamento dos recursos financeiros destinados por modalidade e, em seguida, a identificação dos resultados olímpicos obtidos no mesmo recorte temporal. Para a realização da análise das relações entre os investimentos financeiros realizados e os resultados olímpicos, foram realizadas estatísticas descritivas seguidas do teste estatístico rho $(\rho)$ de Spearman. Pode-se verificar que o referido programa distribuiu o montante de dinheiro de maneira desigual entre as modalidades esportivas analisadas e apenas no último ciclo olímpico (2013-2016) foi encontrada uma correlação positiva entre o valor investido e os números de participações, diplomas e medalhas olímpicas. Concluiu-se, portanto, que o investimento da forma que está acontecendo não garante maiores chances de conquistar medalhas ou diplomas olímpicos.
\end{abstract}

Palavras-chave: Esporte; Jogos olímpicos; Rendimento esportivo; Bolsas de esporte.

\begin{abstract}
The present study aimed to verify whether the financial investments made in a specific way to certain sports modalities provide the country with greater chances of winning medals, diplomas or Olympic participation. The Olympic modalities that had athletes contemplated by the Brazilian Bolsa-Atleta program between 2005 and 2016 were used as a sample. Initially, a survey of the financial resources allocated by modality was carried out, and then the Olympic results obtained in the same section were identified. temporal. For the analysis of the relationships between the financial investments made and the Olympic results, descriptive statistics were performed followed by Spearman's rho $(\rho)$ statistical test. It can be seen that the referred program distributed the amount of money unevenly among the sports analyzed and only in the last Olympic cycle (2013-2016) was a positive correlation found between the amount invested and the number of participations, diplomas and medals olympic games. It was concluded, therefore, that the investment in the way it is happening does not guarantee greater chances of winning Olympic medals or diplomas.
\end{abstract}

Keywords: Sport; Olympic games; Sports performance; Sports bags. 


\begin{abstract}
Resumen
El presente estudio tuvo como objetivo verificar si las inversiones financieras realizadas de manera específica a determinadas modalidades deportivas brindan al país mayores posibilidades de ganar medallas, diplomas o participación olímpica. Se tomaron como muestra las modalidades olímpicas que tuvieron los deportistas contemplados por el programa brasileño Bolsa-Atleta entre 2005 y 2016. Inicialmente se realizó un relevamiento de los recursos económicos asignados por modalidad, y luego se analizaron los resultados olímpicos obtenidos en el mismo apartado. identificado temporal. Para el análisis de las relaciones entre las inversiones financieras realizadas y los resultados olímpicos, se realizó estadística descriptiva seguida de la prueba estadística rho $(\rho)$ de Spearman. Se puede observar que el referido programa distribuyó la cantidad de dinero de manera desigual entre los deportes analizados y solo en el último ciclo olímpico (2013-2016) se encontró una correlación positiva entre el monto invertido y el número de participaciones, diplomas y medallas en juegos olímpicos. Se concluyó, por tanto, que la inversión en la forma en que está sucediendo no garantiza mayores posibilidades de ganar medallas o diplomas olímpicos.
\end{abstract}

Palabras clave: Deporte; Juegos olímpicos; Rendimiento desportivo; Bolsas de deporte.

\title{
1. Introdução
}

Nos últimos anos, muitos países adotam decisões estratégicas para conquistar um número maior de medalhas em eventos internacionais, principalmente em Jogos Olímpicos. Os Jogos Olímpicos reúnem os melhores atletas do mundo, de diferentes modalidades esportivas, a cada quatro anos (Resende, Barbosa \& Mascarenhas, 2013). A competição é considerada um dos eventos mais importantes do mundo esportivo (Calvo-Ortega, 2020). O International Olympic Committee (COI) é a entidade responsável pelo Movimento Olímpico, e propõe que o evento contribua para a construção de um mundo mais pacífico, que além da competição, tenha o objetivo de educar a juventude (International Olympic Committee, 2021). Com relação ao megaevento, diversos estudos já foram realizados sobre os aspectos esportivos (Humphreys, Johnson, Mason \& Whitehead, 2016), ligados ao gênero (Betrán, 2012), midiáticos (Calvo-Ortega, 2020) e econômicos (Brunet, 2011) envolvidos.

Com relação aos aspectos econômicos envolvidos ao esporte olímpico, inclusive, discute-se sobre a associação entre os países que apresentam os maiores números de medalhas no evento serem as nações mais potentes (Betrán, 2012). Sobre os investimentos realizados no esporte, uma estratégia utilizada no início dos anos 90 e, que atualmente ganhou forças, é a ideia de identificar modalidades que possuem uma chance real de sucesso em nível mundial e direcionar os recursos apenas para elas, ou seja, um número relativamente pequeno de esportes (Green \& Oakley, 2001). Todavia, além desta estratégia indagar o fato de os Jogos Olímpicos serem uma pedagogia universal (Betrán, 2012), nem sempre esta é uma estratégia que garante o alcance de resultados esportivos, tendo em vista que existem evidências onde ocorreram quedas no rendimento esportivo mesmo após períodos de elevados investimentos financeiros (De Bosscher, Shibli, Weber, 2018). Entretanto, o investimento direcionado ainda é uma incógnita na literatura internacional e a discussão é ampla sobre ele (Green \& Oakley, 2001; Sam, 2012; De Bosscher et al., 2018; Weber, De Bosscher \& Kempf, 2017), principalmente por representar aspectos ligados à responsabilidade pública (Sam, 2012).

As nações que optam por esta estratégia utilizam parâmetros específicos para realizar a priorização de modalidades, como o fato de alguns esportes possuírem um elevado número de provas, como o Atletismo e a Natação, aumentando as chances de obtenção de medalhas; a existência de modalidades tradicionais culturalmente, como o Judô para o Japão e o Ciclismo para a Holanda; ou ainda, concentrar-se em esportes que apresentam baixo nível de rivalidade e alto equilíbrio competitivo (Zheng, Oh, Kim, Disckson \& De Bosscher, 2017). Diversos são os motivos que levam à escolha desta estratégia de priorização, desde fatores geográficos (Caetano, Sentone, López-Gil, Caetano \& Cavichiolli, 2020), políticos, socioeconômicos (Sentone, López-Gil, Caetano \& Cavichioli, 2019), culturais e/ou a logística de rivalidade com outros países (De Bosscher et al., 2018). 
Como a rivalidade entre as nações aumentou nos últimos anos e a oferta de medalhas continua aproximadamente fixa (Shibli \& Bingham, 2008), os países estão investindo cada vez mais no esporte de alto rendimento, cada um com sua "tática" específica. Um exemplo de priorização de financiamento é o programa "Olympic Winter Institute" da Austrália, em que o apoio é voltado para os esportes de inverno com popularidade pública e sucesso histórico, além de que o atleta precisa ter uma chance razoável de conseguir uma medalha olímpica.

Segundo Castro, Starepravo, Coakley e Souza (2016), a promoção do esporte no Brasil ocorre através de recursos públicos orçamentários e extraorçamentários. O maior programa de financiamento esportivo orçamentário do país é o BolsaAtleta, instituído pela lei no 10.891 de 9 de julho de 2004 e regulamentada pelo Decreto no 5.342 de 14 de janeiro de 2005, tem o objetivo de beneficiar atletas de alto rendimento que possuem resultados nacionais e internacionais em sua modalidade individual olímpica (Brasil, 2004).

De acordo com a legislação brasileira, o Programa Bolsa-Atleta, não segue uma política de investimento direcionado. Os recursos financeiros devem seguir uma prioridade estratégica, deste modo, ao mesmo tempo que investir prioritariamente em poucas modalidades pode identificar um potencial para conquistar medalhas e maiores retornos para o investimento financeiro, há a controvérsia que investir em diversas modalidades pode proporcionar ao país maiores chances de ganhar medalhas em uma ampla gama de esportes.

Visto isso, o objetivo do presente estudo é verificar se os investimentos financeiros realizados de forma direcionada à modalidades esportivas proporciona ao país maiores chances de conquistar medalhas, diplomas ou participações olímpicas. Como hipótese, acredita-se que quanto maior o investimento na modalidade, maior o número de medalhas e participações olímpicas que ela irá obter.

\section{Metodologia}

\section{Desenho do estudo e amostra}

O presente estudo é caracterizado como uma pesquisa descritiva quantitativa ex post facto e foi aprovada pelo Comitê de Ética em pesquisas da Universidade Federal do Paraná, CAAE nº 88770618.4.0000.0102, parecer nº 2.748.001. De acordo com Pereira, Shitsuka, Parreira \& Shitsuka (2018), o método quantitativo envolve a análise do fenômeno em estudo através de medições de grandezas e técnicas matemáticas, o que corrobora com os objetivos deste estudo.

Para realização da análise, utilizou-se como amostra as modalidades olímpicas que possuíram atletas contempladas pelo programa brasileiro Bolsa-Atleta entre 2005 e 2016. Posteriormente, realizou-se o levantamento dos recursos financeiros destinados por modalidade e, em seguida, a identificação das medalhas, diplomas ${ }^{1}$ ou participações olímpicas obtidas por modalidade esportiva no mesmo recorte temporal (2005 a 2016).

\section{Procedimentos e análise de dados}

A escolha do recorte temporal se deu tendo em vista que em 2005 aconteceu a primeira concessão de recursos do programa Bolsa-Atleta e após isto já ocorreram três ciclos olímpicos, sendo eles o da edição da cidade de Pequim (China), Londres (Reino Unido) e Rio de Janeiro (Brasil).

Primeiramente, os dados foram inseridos em uma planilha do Microsoft Excel de acordo com as informações disponibilizadas pelo site $e^{2}$ da Secretaria Especial do Esporte, contendo as seguintes informações: modalidade, edições dos

\footnotetext{
${ }^{1}$ Diploma olímpico é conferido aos oito primeiros classificados em cada prova de cada modalidade esportiva.

${ }^{2}$ https://esporte.gov.br
} 
Jogos Olímpicos, quantidade de atletas por edição, resultado individuais dos atletas, sexo dos atletas, medalhas por modalidade e por edição, quantidade de diploma olímpico, investimento do Programa Bolsa-Atleta por modalidade e por ano.

Para a realização da análise das relações entre os investimentos financeiros realizados e a obtenção de medalhas, diplomas ou participações olímpicas, foram realizadas estatísticas descritivas seguidas do teste estatístico rho $(\rho)$ de Spearman, para verificar a associação entre o valor investido e as demais variáveis (uma vez que os dados não apresentaram distribuição normal por meio do teste de Shapiro-Wilk, $n<50$ ). Todas as análises estatísticas foram realizadas com o software estatístico IBM SPSS Statistics (versão 24) e com o Microsoft Excel 2016, ambos para Windows, mantendo o nível de significância estatística em $\mathrm{p}<0.050$.

\section{Resultados}

Entre 2005 a 2016, o programa Bolsa-Atleta destinou cerca de 500 milhões de reais para 35 modalidades olímpicas, sendo elas: Atletismo, Judô, Handebol, Canoagem, Natação, Vela, Tiro esportivo, Beisebol/Softbol, Taekwondo, Polo aquático, Voleibol, Ciclismo, Boxe, Luta olímpica, Futebol, Basquetebol, Esgrima, Volei de praia, Rugby, Levantamento de peso, Remo, Tênis de mesa, Badminton, Ginastica artística, Hóquei, Tênis, Nado sincronizado, Tiro com arco, Ginastica rítmica, Saltos ornamentais, Triatlo, Pentatlo moderno, Ginástica de trampolim, Hipismo e Golfe. Primeiramente é apontado a distribuição de recursos do programa entre 2005 e 2016.

Figura 1. Distribuição de recursos do programa entre 2005 e 2016.

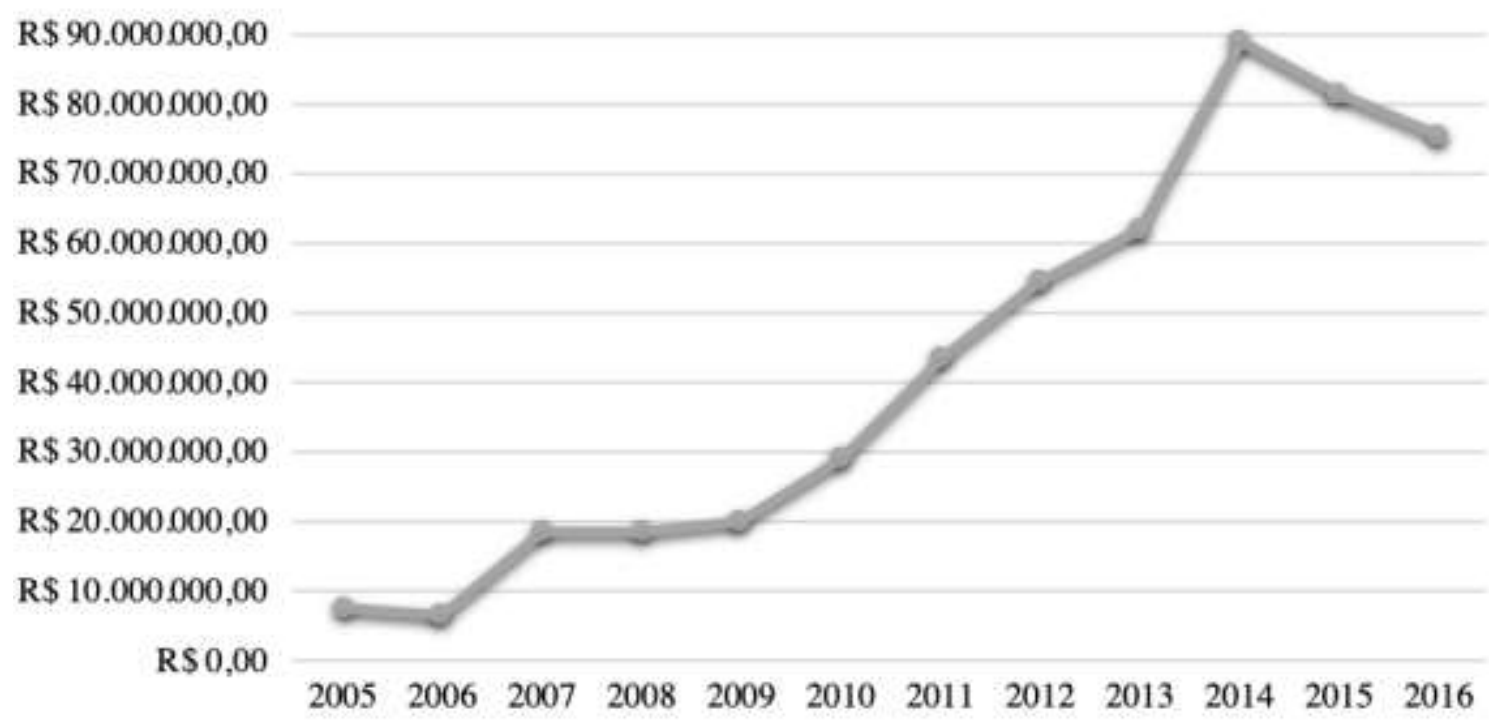

Fonte: Autores (2021).

A Figura 1 aponta o crescimento do valor investimento durante os anos, chegando ao maior valor no ano de 2014 . Na sequência foi analisado a distribuição por modalidade esportiva. 
Tabela 1. Valor investido nos últimos três ciclos olímpicos por modalidade e a relação com participação olímpica, diplomas e medalhas.

\begin{tabular}{|c|c|c|c|c|}
\hline Modalidade & $\begin{array}{c}\text { Valor investido } \\
\mathrm{R} \$(\%)\end{array}$ & $\begin{array}{l}\text { Participação } \\
\text { n (\%) }\end{array}$ & $\begin{array}{l}\text { Diplomas } \\
\text { n }(\%)\end{array}$ & $\begin{array}{c}\text { Medalhas } \\
\text { n }(\%)\end{array}$ \\
\hline Atletismo & $43.969 .195(9,1)$ & $134(13,9)$ & $15(10,6)$ & $4(7,5)$ \\
\hline Judô & $33.633 .380(7,0)$ & $41(4,2)$ & $20(14,1)$ & $10(18,9)$ \\
\hline Handebol & $31.776 .650(6,6)$ & $68(7,0)$ & $3(2,1)$ & - \\
\hline Canoagem & $27.675 .025(5,7)$ & $11(1,1)$ & $1(0,7)$ & $3(5,7)$ \\
\hline Natação & $25.781 .800(5,3)$ & $74(7,7)$ & $15(10,6)$ & $5(9,4)$ \\
\hline Vela & $22.022 .520(4,6)$ & $36(3,7)$ & $12(8,5)$ & $4(7,5)$ \\
\hline Tiro esportivo & $21.980 .280(4,6)$ & $13(1,3)$ & $1(0,7)$ & $1(1,9)$ \\
\hline Beisebol/Softbol & $19.196 .500(4,0)$ & - & - & - \\
\hline Taekwondo & $18.219 .010(3,8)$ & $9(0,9)$ & $3(2,1)$ & $2(3,8)$ \\
\hline Polo aquático & $16.838 .330(3,5)$ & $26(2,7)$ & $2(1,4)$ & - \\
\hline Voleibol & 15.537.111 (3,2) & $72(7,4)$ & $10(7,0)$ & $5(9,4)$ \\
\hline Ciclismo & $15.369 .530(3,2)$ & $24(2,5)$ & $1(0,7)$ & - \\
\hline Boxe & $15.224 .770(3,2)$ & $25(2,6)$ & $9(6,3)$ & $4(7,5)$ \\
\hline Luta olímpica & $14.199 .750(2,9)$ & $7(0,7)$ & $1(0,7)$ & - \\
\hline Futebol & $13.901 .260(2,9)$ & $108(11,2)$ & $6(4,2)$ & $4(7,5)$ \\
\hline Basquetebol & $13.616 .320(2,8)$ & $60(6,2)$ & $1(0,7)$ & - \\
\hline Esgrima & $12.339 .250(2,6)$ & $18(1,9)$ & $3(2,1)$ & - \\
\hline Vôlei de praia & $11.649 .170(2,4)$ & $24(2,5)$ & $6(4,2)$ & $6(11,3)$ \\
\hline Rugby & $11.647 .970(2,4)$ & $24(2,5)$ & - & - \\
\hline Levantamento de peso & $11.283 .790(2,3)$ & $8(0,8)$ & $3(2,1)$ & - \\
\hline Remo & $10.166 .390(2,1)$ & $14(1,4)$ & 0 & - \\
\hline Tênis de mesa & $10.033 .210(2,1)$ & $16(1,7)$ & $1(0,7)$ & - \\
\hline Badminton & $8.514 .675(1,8)$ & $2(0,2)$ & - & - \\
\hline Ginastica artística & 7.977.520 (1,7) & $25(2,6)$ & $16(11,3)$ & $4(7,5)$ \\
\hline Hóquei & $7.922 .250(1,6)$ & $16(1,7)$ & - & - \\
\hline Tênis & $6.684 .690(1,4)$ & $15(1,6)$ & $3(2,1)$ & - \\
\hline Nado sincronizado & $6.108 .810(1,3)$ & $13(1,3)$ & $1(0,7)$ & - \\
\hline Tiro com arco & $5.684 .370(1,2)$ & $8(0,8)$ & - & - \\
\hline Ginastica rítmica & $4.738 .480(1,0)$ & $11(1,1)$ & - & - \\
\hline Saltos ornamentais & $3.700 .490(0,8)$ & $16(1,7)$ & $4(2,8)$ & - \\
\hline Triatlo & $3.460 .680(0,7)$ & $8(0,8)$ & - & - \\
\hline Pentatlo moderno & $3.323 .820(0,7)$ & $4(0,4)$ & $1(0,7)$ & $1(1,9)$ \\
\hline Ginástica de trampolim & $3.247 .340(0,7)$ & $1(0,1)$ & - & - \\
\hline Hipismo & $2.401 .400(0,5)$ & $33(3,4)$ & $4(2,8)$ & - \\
\hline Golfe & $2.088 .190(0,4)$ & $3(0,3)$ & - & - \\
\hline Total & $481.913 .926(100,0)$ & $967(100,0)$ & $142(100,0)$ & $53(100,0)$ \\
\hline
\end{tabular}

Fonte: Autores (2021).

Na Tabela 1 estão apresentados os valores direcionados à cada modalidade esportiva específica, as participações, diplomas e medalhas Apesar do governo brasileiro afirmar que não existe recurso direcionado no programa analisado (Brasil, 2004), quando observado o montante de dinheiro destinado a cada modalidade olímpica, foi visível a desigualdade entre os 
recursos destinados às modalidades.

Para poder identificar possíveis relações entre os recursos financeiros e as participações, diplomas e medalhas olímpicas, primeiramente realizou-se a distribuição dos dados por ciclo olímpico, disposto na Figura 2.

Figura 2. Investimento, número de bolsas, participações olímpicas, diplomas olímpicos e medalhas olímpicas por ciclo olímpico.

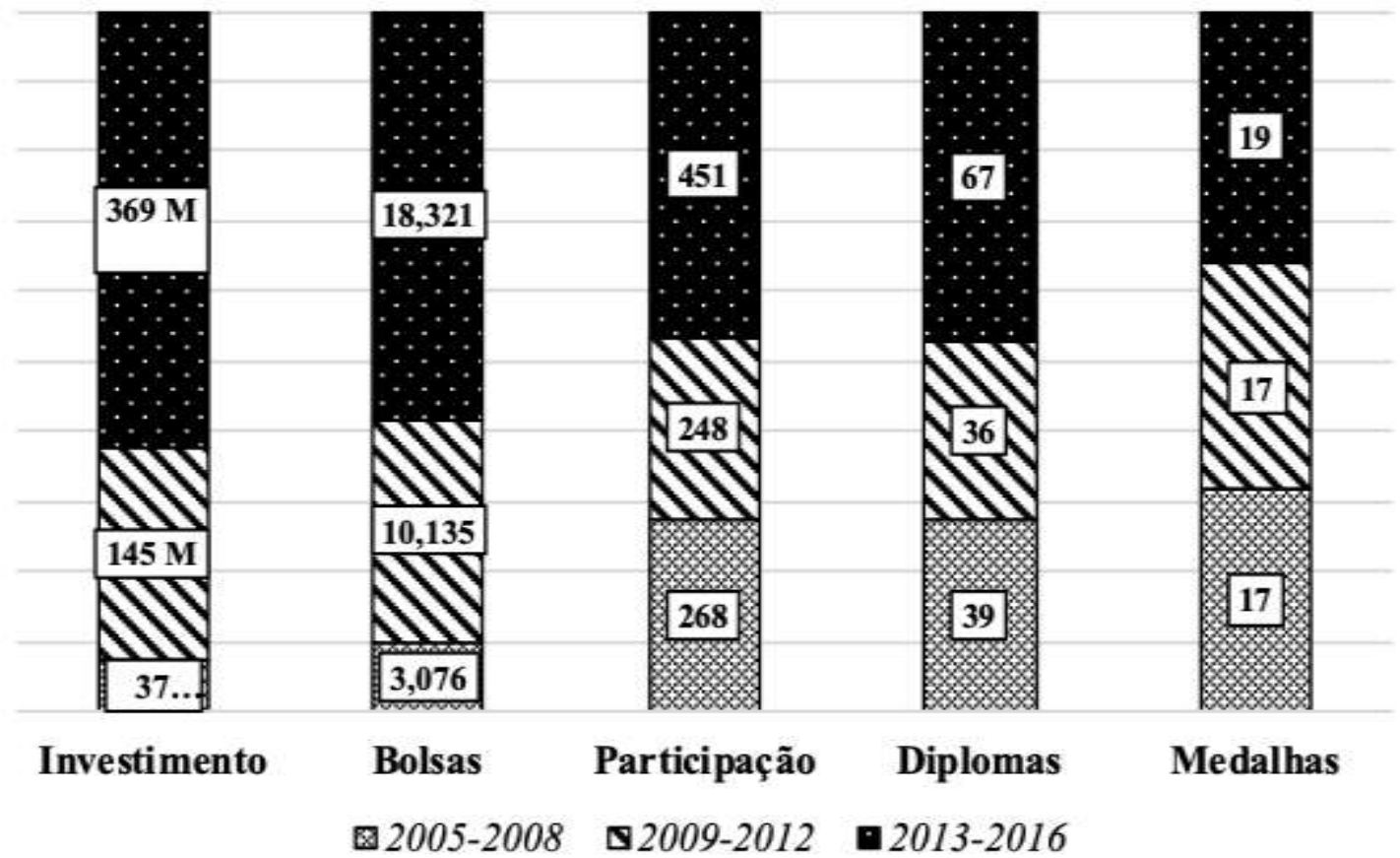

M = Milhões de reais. Fonte: Autores (2021).

Na Figura 2 é visível o aumento do valor investido entre os ciclos, chegando a 369 milhões no último (2013-2016), consequentemente, aumentou o número de bolsas. E houve também, o aumento nas participações, diplomas e medalhas olímpicas.

Com o intuito de verificar a existência de associações entre os valores investidos e os resultados esportivos, foi realizado o teste estatístico rho $(\rho)$ de Spearman (Tabela 2).

Tabela 2. Valor investido por ciclo olímpico em relação a participação, diplomas e medalhas olímpicas.

\begin{tabular}{cccc}
\hline Ciclo olímpico & Participação & Diplomas & Medalhas \\
\hline $\begin{array}{c}\text { Valor investido } \\
(2005-2008)\end{array}$ &, 320 &, 312 &, 136 \\
\hline $\begin{array}{c}\text { Valor investido } \\
(2009-2012)\end{array}$ &, 320 &, 312 &, 136 \\
\hline $\begin{array}{c}\text { Valor investido } \\
(2013-2016)\end{array}$ &, $528^{* *}$ &, $427^{*}$ &, $622^{* * *}$ \\
\hline $\begin{array}{l}\text { Valor investido } \\
(2005-2016)\end{array}$ &, $497^{* *}$ &, $473^{* *}$ &, $527^{* *}$ \\
\hline
\end{tabular}

${ }^{*} \mathrm{p}<, 050 ; * * \mathrm{p}<, 001$. Fonte: Autores (2021). 
Por meio do teste e como aponta a Tabela 2, pode-se observar que no último ciclo olímpico (2013-2016) foi encontrada uma correlação positiva entre o valor investido e a participação ( $r=.528$ ), o numero de diplomas (r=.427) e o número de medalhas ( $\mathrm{r}=.622)$, entretanto, esta relação positiva não foi observada no primeiro ciclo olímpico (2005-2008) e no segundo (2009-2012).

\section{Discussão}

$\mathrm{O}$ objetivo do presente estudo foi verificar se os investimentos financeiros realizados de forma direcionada às modalidades esportivas proporciona ao país maiores chances de conquistar medalhas, diplomas ou participações olímpicas. Primeiramente, é visto que existem modalidades que ganham mais que outras, entretanto, nega-se a hipótese que quanto maior o investimento na modalidade, maior o número de medalhas e participações olímpicas. Em relação aos ciclos olímpicos, apenas no último (2013-2016) foi encontrada correlação positiva entre o valor investido, e os números de participações, diplomas e medalhas olímpicas.

Deste modo, pode-se perceber que além de ferir a proposta de pedagogia universal do movimento olímpico (Betrán, 2012), os investimentos priorizados não garantem o aumento na obtenção de resultados. Priorizar modalidades esportivas específicas faz com que os investimentos ocorram direcionados desde o esporte de base, e isso, contradiz um dos valores dos Jogos Olímpicos, que é universalizar o esporte desde a juventude. Pode-se perceber que embora o Atletismo possua o maior valor investido assim como o maior número de participações, apresenta um número de diplomas e medalhas inferior que diversas outras modalidades olímpicas, corroborando com os apontamentos de Bosscher et al. (2018) sobre nem sempre a priorização ser uma estratégia de financiamento eficiente e, mesmo após períodos de elevados investimentos financeiros os resultados esportivos podem não responder as expectativas.

Além disto, notou-se que o Handebol não se apresentou como um esporte rentável, pois, embora seja a terceira modalidade que mais recebeu recursos do programa, não possui nenhuma medalha olímpica. Em contrapartida, modalidades como o Volei de Praia e Ginástica Artística apresentaram um valor relativo por medalhas menor.

Com relação ao valor de investimento por ciclo olímpico, é visível que houve o aumento no número de diplomas olímpicos, assim como no número de medalhas no ciclo 2013 a 2016, apresentando uma correlação positiva. De acordo com o Ministério do Esporte (2016), a delegação brasileira nos Jogos Olímpicos do Rio de Janeiro (2016) contou com 465 atletas, sendo 358 bolsistas (77\%), sendo a maior da história. Porém, os Jogos Olímpicos do ano de 2016 acontecerem no Rio de Janeiro (Brasil) e esse foi um dos motivos para aumentar o número de participações, já que o país sede possuía garantia de vagas de forma automática. Da mesma forma, o aumento no valor investido pode ampliar a possibilidade dos atletas se dedicarem mais ao esporte competitivo, aumentando o tempo de treinamento, as capacidades físicas dos atletas, a qualidade de treinamento, as possibilidades de competir em competições com qualidades superiores. Todavia, não se pode descartar a possibilidade de outras fontes de recurso existirem, fator este determinante para o desenvolvimento do esporte (Berry \& Manoli, 2018).

Estes achados questionam as relações existentes entre o financiamento e o desempenho esportivo a partir de uma perspectiva direta, comprovando os apontamentos de Sam (2012), ao afirmar que existem diversos impedimentos e implicações na política esportiva de descentralização de recursos.

Entende-se que há diferenças entre as modalidades, como por exemplo o número de provas de cada uma delas, enquanto o Voleibol em uma edição olímpica, pode alcançar apenas seis medalhas (sexo feminino e masculino), o Atletismo possui a chance de 75 medalhas, sendo 22 provas para ambos os sexos, duas apenas masculinas e uma feminina. Mas há modalidades que recebem mais incentivo e possui menos provas, não parecendo ser um método do governo brasileiro. 
Ainda, sabe-se que propor uma modificação na alocação de recursos pode gerar tensões específicas, principalmente, se a proposta for de reduzir os investimentos direcionados aos esportes "prioritários" (Sam, 2012) considerando que existiram princípios influenciadores desta priorização. Todavia, devido a essa circunstância, foi comparado o valor investido nos últimos três ciclos olímpicos com a participação olímpica do Brasil, além do número de diplomas (os primeiros oito colocados) e medalhas olímpicas, com o intuito de destacar possíveis pontos de questionamento.

Realizando a análise comparativa entre os números de medalhas conquistadas, é notável uma evolução entre os ciclos e a relação com o Programa Bolsa-Atleta: 2008 conquistou 15 medalhas sendo 07 bolsistas, 2012 conquistou 17 medalhas sendo 10 bolsistas, e 19 medalhas em 2016 todas conquistadas por bolsistas. Entretanto, também foi possível identificar que nem sempre o investimento realizado nas modalidades atua de forma diretamente proporcional com relação ao número de resultados olímpicos.

Com base nos dados apresentados, entendemos que o presente estudo pôde colaborar para uma melhor aplicação das políticas públicas no esporte. A pesquisa foi a primeira no Brasil que investigou a relação de dinheiro investido em um programa de financiamento esportivo, dessa forma, reconhecemos que a multicausalidade pode ser uma limitação do presente estudo, tendo em vista a dificuldade em separar os efeitos sociais produzidos pela politica publica e os efeitos sociais produzidos por outras causas. Admite-se que o subsídio do governo não é o único meio de testar o país em Jogos Olímpicos, todavia, afirma-se a necessidade de avaliação nesta política pública, visando aumentar a eficiência do direcionamento de recursos públicos.

\section{Considerações Finais}

Apesar do Brasil relatar que não há um investimento direcionado para determinadas modalidades esportivas, é possível concluir que há modalidades que recebem mais que outras. Porém a forma que o investimento está acontecendo não garante maiores chances de conquistar medalhas nem diplomas olímpicos. Deste modo, a hipótese de que quanto maior o investimento na modalidade maior o número de medalhas e participações olímpicas pode ser negada.

Há modalidades como a Ginástica Artística e o Vôlei de praia que são mais rentáveis para o governo, quando comparado por exemplo com o Atletismo que hoje é a que mais recebe e com o Tiro Esportivo.

Acredita-se que o Programa Bolsa-Atleta é uma política pública importante para o cenário brasileiro pois esta é a principal forma de investimento individual para atletas, porém, os recursos deste programa poderiam ser melhor distribuídos. Uma sugestão para estudos futuros é analisar quais são as modalidades mais rentáveis e assumir um investimento direcionado.

\section{Referências}

Berry, R., \& Manoli, A. E. (2018). Alternative revenue streams for centrally funded sport governing bodies. International Journal of Sport Policy and Politics, 10(3), 429-500. https://doi.org/10.1080/19406940.2017.1387587

Betrán, J. O. (2012). Juegos Olímpicos Londres 2012: la olimpiada de las mujeres. Apunts. Educación Física y Deportes, 3(109), 7-10. https://www.raco.cat/index.php/ApuntsEFD/article/view/261233

Brasil. (2004). Lei no 10.891, de 09 de julho de 2004. Institui o Bolsa-Atleta. http://www2.camara.leg.br/legin/fed/lei/2004/lei-10891-9-julho-2004-532976publicacaooriginal-15545-pl.html

Brunet, F. (2011). Análisis del impacto económico de los Juegos Olímpicos. In E. F. Penã, B. Cerezuela, M. G. Benosa, C. Kennett, \& M. de M. Spà (Eds.), Mosaico Olímplico. Investigación multidisciplinar y difusión de los estudios olímpicos. (pp. 207-218). Ceo-UAB-Ayuntamiento de Barcelona. https://www.mhcat.cat/content/download/28582/281631/file/Moisaico_Ol+¡mpico_CEO-UAB.pdf

Caetano, C. I., Sentone, R. G., López-Gil, J. F., Caetano, H. B. S., \& Cavichiolli, F. R. (2020). Influência do tamanho e densidade populacional no rendimento esportivo da ginástica artística brasileira (Influence of population size and density on sports performance of Brazilian artistic gymnastics). Retos, 38, 66-70. https://recyt.fecyt.es/index.php/retos/article/view/74338

Calvo-Ortega, E. (2020). La cobertura informativa de las deportistas durante los Juegos Olímpicos.[News Coverage of Women Athletes during the Olympic Games]. RICYDE. Revista Internacional de Ciencias Del Deporte, 16(61), 267-284. https://doi.org/10.5232/ricyde2020.06103 
Research, Society and Development, v. 10, n. 3, e10910312699, 2021

(CC BY 4.0) | ISSN 2525-3409 | DOI: http://dx.doi.org/10.33448/rsd-v10i3.12699

Castro, S. B. E. De, Starepravo, F. A., Coakley, J., \& Souza, D. L. De. (2016). Mega sporting events and public funding of sport in Brazil (2004-2011). Leisure Studies, 35(3), 369-386. https://doi.org/10.1080/02614367.2015.1037789

De Bosscher, V., Shibli, S., \& Weber, A. C. (2019). Is prioritisation of funding in elite sport effective? An analysis of the investment strategies in 16 countries. European Sport Management Quarterly, 19(2), 221-243. https://doi.org/10.1080/16184742.2018.1505926

Green, M., \& Oakley, B. (2001). Elite sport development systems and playing to win: uniformity and diversity in international approaches. Leisure Studies, 20(4), 247-267. https://doi.org/10.1080/02614360110103598

Humphreys, B. R., Johnson, B. K., Mason, D. S. \& Whitehead, J. C. (2018). Estimating the Value of Medal Success in the Olympic Games. Journal of Sports Economics, 19(3), 398-416. https://doi.org/10.1177/1527002515626221

International Olympic Committee (2012). How we do it. https://www.olympic.org/how-we-do-it

Ministério do Esporte (2016). Bolsa Atleta Pódio. Recuperado em 12 abril, 2019. http://www.brasil2016.gov.br/pt-br/incentivo-ao-esporte/bolsa-atleta-podio.

Pereira, A. S., Shitsuka, D. M., Parreira, F. J., \& Shitsura, R. (2018). Metodologia da pesquisa científica. UFSM. https://repositorio.ufsm.br/bitstream/handle/1/15824/Lic_Computacao_Metodologia-Pesquisa-Cientifica.pdf?sequence=1

Resende, M. T., Barbosa, W. M., \& Mascarenhas, F. (2013). O financiamento do esporte olímpico no brasil: uma análise do ciclo de londres (2009-2012). Revista de Ciencias Sociales, 86-110. https://www.redalyc.org/articulo.oa?id=708/70829847006

Sam, M. (2012). Targeted investments in elite sport funding: Wiser, more innovative and strategic? Managing Leisure, 17(2-3), 207-220. https://doi.org/10.1080/13606719.2012.674395

Sentone, R. G., López-Gil, J. F., Caetano, C. I., \& Cavichiolli, F. R. (2019). Relationship between human development index and the sport results of Brazilian swimming athletes. Journal of Human Sport and Exercise, 14(5), 2009-2018.

Shibli, S., \& Bingham, J. (2008). A forecast of the performance of China in the Beijing Olympic Games 2008 and the underlying performance management issues. Managing Leisure, 13(3-4), 272-292. https://doi.org/10.1080/13606710802200977

Weber, A. C., De Bosscher, V., \& Kempf, H. (2017). Positioning in Olympic Winter sports: analysing national prioritisation of funding and success in eight nations. European Sport Management Quarterly, 18(1), 8-24. https://doi.org/10.1080/16184742.2017.1336782

Zheng, J., Oh, T., Kim, S., Dickson, G., \& De Bosscher, V. (2018). Competitive balance trends in elite table tennis: the Olympic Games and World Championships 1988-2016. Journal of Sports Sciences, 36(23), 2675-2683. https://doi.org/10.1080/02640414.2017.1375174 